\title{
Peer-Led Group Supervision A model to support and inspire social work students to be 'active discoverers and constructors of their own knowledge'.
}

\section{Jo Strang}

\begin{abstract}
This article presents the research findings of a pilot study of 'Peer-led Group Supervision' introduced for undergraduate social work students at a university in the United Kingdom. The pedagogical motivation for designing this model is considered, the pilot study is described and the findings of the student evaluation presented. There is evidence of positive student feedback, with this group setting having enabled students to benefit from peer support, knowledge exchange and an opportunity to discuss learning from different work-based learning experiences. Recommendations are made regarding how this model could be developed to further the learning opportunities for social work students and potentially how it could be used to incorporate active learning opportunities within distant learning provision.
\end{abstract}

Keywords: Peer-learning; group supervision; social work education; practice learning; peer education; social work skills; work-based learning.

1. Open University

Address for correspondence: jo.strang@open.ac.uk

Date of first (online) publication: 9th November 2021

Acknowledgement: This research was undertaken while the author was a Senior Lecturer at the University of Chichester

69 J. of Practice Teaching \& Learning: Advance $\odot$ w $b b$ 


\section{Introduction}

Students' experience of group supervision is so positive that social work education programmes might usefully explore the possibility of putting systems in place that would make group practice learning available to all students not just those who happen to share a practice teacher with some other students.(Lindsay 2003, p.17)

Taking on board Lindsay's observation of the value of group supervision within social work education, a 'peer-led group supervision model' was piloted with BA Social Work students who were undertaking their field-work placements. Social Work Education in England requires that two field-work placements are completed and assessed against the Professional Capabilities Framework (BASW, 2018). All students involved in this pilot study were either undertaking their 70-day or 100-day field placement.

The intention was to create a group learning environment which could encourage students to 'become active discoverers and constructors of their own knowledge' (Barr and Tagg, 1995); allowing them scope and opportunities to be responsible for their own learning and requiring them to engage in self-reflection and application of theory to practice. The motivation to create a different learning environment arose from placement organisations providing feedback that some students presented as lacking in confidence and struggling to show initiative in busy, unpredictable working environments. In addition, feedback at annual Quality Assurance meetings and Practice Assessment Panels (where student field-work portfolios are reviewed) regularly noted a lack of in-depth self-reflection and application of theory and legislation to practice. This pilot sought to respond to this feedback and was designed with the intention of exploring whether a group learning environment could positively impact students' learning and development. The groups aimed to provide students with an opportunity to:

- Safely explore and discuss placement-related issues

- Exchange newly acquired practice knowledge

- Practice key skills in communicating and participating in group meetings, akin to many meetings which take place in Social Work practice

- Share self-reflection with other students

- Consider real-life ethical practice issues

70 J. of Practice Teaching \& Learning: Advance (C) wEb 
- Reflect on skills in anti-oppressive practice

- Apply theory to practice experiences

- Recognise underpinning legislation

These areas of learning are key components of a more traditional individual supervision model, between a student social worker and their assessor, (known in England by the title Practice Educator (PE)). However, the focus on peer-led supervision within a group learning setting was very deliberate as it attempted to introduce a change in power dynamics. A PE attended every group but the structure was such that the PE would undertake the role of observer and would actively engage only if required. The expectation was that students themselves stepped into the role of running the groups, supporting and encouraging participation between each other and taking responsibility for their own part within the process; rather than waiting for the PE to lead and facilitate the group.

\section{Underpinning theories of learning and teaching}

This model was based on the concept of Higher Education being studentcentred/learning-oriented, rather than teacher-centred/content-oriented. The intention being to move away from a more traditional view of an educator transmitting knowledge to a student and instead to embrace a constructivist notion of learning. In this regard, the approach endeavoured to recognise that all social work students start their journey in social work education with prior knowledge, skills, and personal and professional lived experience. It sought to create an effective learning environment where students could make connections between what they already knew and what was new, in order that they could make meaning and identify connections (Scales 2017, pp.15-19). Although theoretically this approach was both person-centred and strengths-based - mirroring the principles of good social work practice and setting out to appreciate and build on the rich diversity of experience that already existed - there was also the potential for students to find this more active style of learning daunting. Often students have become accustomed to and therefore comfortable with teacher-centred/content-oriented learning and this encouragement for more free-thinking and personal reflection can feel de-skilling as it pushes students outside of their comfort zone. However, in terms of training social

71 J. of Practice Teaching \& Learning: Advance $\odot$ wEbb 
work students to become professionally curious and more confident in their assessment, communication and decision-making skills, offering a different type of learning environment was considered beneficial in providing time and space to discuss thoughts, feelings and practice experiences, whilst also rehearsing key skills.

Barnett defines the difference between knowledge and knowing and proceeds to explore the connection between knowing and becoming (Barnett 2009, pp.432-434). He suggests that 'the process of coming to know has person-forming properties' and this perspective builds further on the idea that the process of learning and active engagement with both knowledge and learning experiences can lead to change and transformation (Barnett 2009; p.435). Quantifying and mapping this type of learning experience is problematic and not always tangible and yet studies around the development of professional identity for social work students also suggest that active engagement with both people (colleagues, supervisors, role models) and knowledge (codes of practice, regulatory requirements) encourages this process of emerging professional identity. Wiles' (2017) research into 'what professional identity is and how social workers acquire it' identified three themes with regard to students' construction of their professional identity; firstly, professional identity in relation to desired traits, secondly through developing a sense of shared identity with other social workers and thirdly as a process of individual development (Wiles 2017, p.6). Student feedback in the study is rich and diverse. As students discuss their reflections of professional identity, they refer to increased confidence and autonomy, ability to practice in line with professional codes of practice and a sense of shared collective identity. Wiles also notes the relevance of identity work, with students reflecting on changes to their personal identity and recognizing the relevance of self in regard to their practice and experiences of social work education (Wiles 2017, p.15). These research findings point to the importance of professional identity evolving as part of a process, placing even greater importance on the need to create learning environments which can encourage active and deep learning. Although developing professional identity was not a central aim to the design process of this pilot model, all elements of the learning strategy focused on creating a learning environment that would provide a safe space for further development of skills, values and knowledge relevant to the social work profession. Using a group setting, the intention was to create the opportunity for discussion between peers and in the company of a Practice Educator.

72 J. of Practice Teaching \& Learning: Advance $\odot$ w $\& b$ 


\section{The role of groupwork in social work practice and higher education}

Groups have long been used in both Higher Education and Social Work practice to benefit the experiences of participating individuals. Doel states that 'groups are central to human experience' (in Teater, 2014, p.239) and when used with a planned learning outcome for those involved, the group is usually founded on the premise of learning from others who are 'in the same boat' and providing mutual support due to shared experiences or a shared identity. The theory of groupwork proffers that 'groups create an environment where individuals can collectively influence each other', offering support, feedback and even challenge accordingly, with the intention of further learning for each group member (Teater, 2014, p.241).

When groupwork theory is applied to either a teaching environment or a social work practice situation, then intended learning outcomes need to be clear. A group of people are brought together with a plan or purpose of what the group experience can achieve. Group activity takes place as far as interaction, communication and exchange with the aim that change is achieved in some form, whether this be the learning outcomes being met or empowerment, personal growth and development opportunities for the individuals involved in the group work process (Crawford et al., 2015, p.17).

Whilst learning through interactions with others is a prominent positive principle of groupwork, this way of teaching and learning does not come without its challenges, precisely because it involves learning through interactions with others! Theories of groupwork processes and group dynamics are well-documented and overall, both the opportunity and the risk of groups is that the interchange between people can be unpredictable, challenging and lead to a wide range of incidental learning. As far as social work education, for this pilot study the uncertainty was deemed a risk worth taking, because social work practice often involves working with family groups or groups of professionals with the likelihood that not everyone will agree all of the time. Hence, rather than avoid opportunities to learn through the ups and downs of the lifecycle of a group, it was considered preferable to allow students the opportunity to engage in a groupwork process and build confidence, coping skills and intervention skills prior to qualification as social workers.

73 J. of Practice Teaching \& Learning: Advance $\odot$ w Eb 


\section{Group supervision}

Groups have also been used as a learning environment for supervision which in the UK is known to be a defining feature of high-quality social work practice. The expectation is that social workers and students regularly receive time and space to reflect on and discuss their work, usually with a more experienced social worker. Historically, supervision has been recognized to have three main functions; educational, supportive and administrative (Kadushin, 1992). This provides opportunities to learn in a variety of ways, to receive support for personal experiences that may impact professional practice and to ensure organizational requirements are being met via the social work practice undertaken. Advantages of a group model are recognized - the sharing of information, peer support and an opportunity to analyse and reflect on practice - but these run alongside concerns that group dynamics may negatively impact on individuals causing isolation, competition or reliance on perceived 'competent' students (Showell et al., 2015, pp.29-30). Student accounts also offer conflicting feedback about the success of group supervision and whilst often thought to be cost-effective, the varied outcomes and need for skilled leadership appear to have led one-to-one supervision arrangements to remain the norm (Doel, 2010, p.112-114). A further concern is that an individualized learning and support plan for a student could become lost within a group setting, Indeed, this is why this pilot model sort to replace only one individual supervision session per month; seeking to provide an additional learning experience rather than reducing the availability of support and education in one-to-one supervision sessions.

\section{What is Peer-led group supervision?}

Students often learn informally through conversations with peers however these groups were set-up as a formal learning experience with an expectation that learning from peers would take place. Borders notes, 'peer group supervision is widely advocated but infrequently described.' (Borders, 2001, p.248) Despite this apparent lack of clarity, research in a variety of fields provides evidence that peer group supervision can be highly beneficial; whether in the form of a peer review process, group supervision, personal growth groups, peer consultation groups or leaderless peer supervision groups (Borders ,2001; Valentino et al., 2016; Rowell \& Benshoff, 2008;

74 J. of Practice Teaching \& Learning: Advance (C) wEb 
Topping, 2005; Counselman \& Weber, 2004). Whilst the definitions vary, probably with the intention of attaching a label descriptor that is relevant for the focus and format of the specific group experience being referred to at the time, the shared beliefs of those who have embarked on setting up such groups can broadly be summarised as follows:

1. A group setting which poses considerable opportunities to allow for support and problem-solving between people who find themselves in a similar situation

2. An opportunity for learning between peers which can be hugely effective in reducing the impact of a power differential between a teacher and a group of learners

3. The process of learners actively sharing their thoughts, feelings and experiences which can have a significant impact on the learning deriving from discussing, sharing, giving and receiving feedback.

Lindsay (2003) presents a list of thirteen reasons why group supervision is effective and economical, noting that sharing problems allows them to become less personal and to be dealt with more objectively, recognizing that an honest exchange about experiences can reduce student worry and highlighting that being engaged in this supervision process can be experienced by students as empowering (Lindsay, 2003, p.3). That said, the process of working in groups is, as already noted, never without a risk of challenge or of the process not working for all. Cautionary points are outlined regarding potential challenges or disadvantages:

- the risk of not meeting individual needs

- the potential for rivalry, competition and negative feedback

- complicated group dynamics evolving

- the potential opportunity for some participants to remain quiet and avoid engagement in the learning process

- The importance of having an experienced facilitator (Lindsay, 2003, p.3)

Although now a familiar term, 'peer learning is not a single, undifferentiated educational strategy' and it therefore 'remains abstract' (Boud et al., 2001, p.3). Increasingly within Higher Education it is being more formally acknowledged within curriculum design. Cohen and Sampson assert that 'whatever the form peer learning takes... it is most successful when it is designed as

75 J. of Practice Teaching \& Learning: Advance $\odot$ w $\& b$ 
an integral part of the overall course or subject' (in Boud et al. 2001, p.21). Thus the design features of the group learning environment - context, learning outcome and general goal - are all key to preparatory decision-making about how to best create a beneficial learning environment. For this pilot study, a fixed agenda for the group session provided an outline structure from which student learning could evolve and blossom. It covered key themes relevant to field-work practice experiences and underpinning knowledge, skills and values and was underpinned by a belief that sharing and discussing experiences could enhance the learning of the group members.

\section{Peer-leadership}

To fully understand this proposed model of peer-led group supervision, clarification of the term 'peer-led' is also required. 'Peer learning' often presumes that the learning environment or group experience is 'peer-led', denoting the absence of a professional or expert and making a distinction between peer-led and professional-led group experiences. However, the responsibilities of the participants - with regard to what they might be expected to lead within a peer group process - should not be muddled with the presumption that peer-led must mean that there is no involvement of an expert or professional. For example, in some support groups, a professional has set-up the group experience, but would not attend the group sessions to prevent any risk of inhibiting the opportunity for sharing of personal experiences or negatively impacting the power dynamics. In contrast, in an education setting, whilst the learning activity may well be peer-led, the instruction or task may be provided by a lecturer, with their ongoing oversight to ensure learning takes place as envisaged. Although notably vague and inconclusive in definition, these terms are all worthy of thought and reflection in order to meaningfully consider the purpose and practice of any models regarding peer-learning and group supervision. It is therefore essential that $a$,

purposeful and systematic approach (is) taken by teachers to include peer learning in the design and implementation of courses and then monitor the process of these activities as well as the outcomes. (Cohen \& Sampson in Boud, 2001, p.50)

76 J. of Practice Teaching \& Learning: Advance $\odot$ w $\& b$ 
Indeed, this is the purpose of this evaluative research following the pilot study. In the context of Barr and Tagg's description of a required shift in undergraduate education from being an 'instruction paradigm' to becoming a 'learning paradigm', this model was introduced on the premise that a

learning environment or approach is judged in terms of its impact on learning. If learning occurs, then the environment has power. (Barr and Tagg, 1995)

Consequently, in order to establish if this learning environment did indeed have power, a review of the process and outcome from the students' perspective was essential.

\section{The model}

All student social workers in England currently undertake two practice placements during their social work degree. For each placement they are supported by a qualified Practice Educator who assesses their practice and provides regular supervision sessions throughout the placement duration, during which casework, theory, anti-oppressive practice, ethics, legislation, and many other topics, are discussed. In most cases, the supervision is offered as a one-to-one experience between student and Practice Educator, with some occasional opportunities for a group supervision experience.

Taking on board the cautionary point that students need reassurance that they will continue to receive individual support and supervision, just one individual session per month was substituted with a peer-led group supervision session. Students were arranged, according to the geography of their placement organisations, into groups of 6-8 students and met for a planned session of $1 \frac{1}{2}$ hours within placement time. The groups took place at different placement locations, as organized and co-ordinated by the students themselves. The students remained within their year groups (either undertaking first placements of 70 days or second placements of 100 days) but this pilot involved all BA students out on placement in this academic year.

Due to this arrangement of replacing a supervision session and thus being a requirement with regard to practice learning arrangements, the model design required a member of staff (qualified as a social worker) to be present at each group in an observational role. The rationale for this

77 J. of Practice Teaching \& Learning: Advance $\odot$ w Eb 
was two-fold. Firstly, if students didn't see this as a formal requirement it was felt there was less chance of them attending and 'buying-in' to this model of learning. Secondly, there was a real hope that significant learning was achieved through discussion, reflection and problem-solving and by having a qualified social worker present the intention was that if required they could step in to steer the group back on course, or enhance learning and discussion further. In this sense the risk of this placement time not being used for meaningful learning was minimized.

Each group was supported by a Practice Educator or Link Tutor who attended in an observational role to support the process of the session but with a clear understanding that the group was to be student-led and student-run. The group were provided with an 'agenda' which provided a basic format for the group, designed to provide sufficient structure such that the students felt they had clarity and purpose to lead a group through the process, but with enough flexibility to allow the group to focus on key issues that came from their own unique group discussions. The following elements were included, in relation to specified learning outcomes.

Table 1

Elements of group process and specific learning outcomes

1. Element: Traffic-light check-in at start of each group (red/amber/green depicting how they were feeling and a brief explanation as to why)

Learning outcome: To provide a clear beginning for the group; encourage honesty and sharing; to provide the opportunity of minimizing fear and anxiety due to others being 'in the same boat'; to offer a starting point for problem-solving and solution-focused practice.

2. Element: One student to chair and one student to minute and for all to have experience of these roles. Students to also arrange timings and room bookings

Learning outcome: An opportunity for all to rehearse these key skills relevant to practice; managing time; managing group dynamics; recording discussions clearly and succinctly in a written form; organising and communicating information effectively.

3. Element: Two students to bring a piece of case work for discussion and exploration to each group

Learning outcomes: To prompt discussion, with the expectation that self-reflection, theory to practice, relevance of legislation and sharing of useful resources all be

78 J. of Practice Teaching \& Learning: Advance (C) wEb 
shared in response to the case work presented. Ethics, anti-oppressive practice, confidentiality, and safeguarding issues to be considered.

Exposure to different types of social work in different fields to be enabled.

Encouragement to refer back to the Professional Capability Framework (BASW, 2018)

4. Element: 'Any other business'

Learning outcome: To allow scope for sharing further information and discussing any relevant points, linked to both academic and fieldwork requirements of the course

\section{Methodology}

In this pilot study 62 students were involved, arranged into 8 groups and supported by 5 social work professionals (3 freelance Practice Educators, 1 University Tutor and 1 University Tutor/Practice Educator). A Bristol Online Survey was sent to all students with the intention of evaluating;

1. the students' experiences of the process of peer-led group supervision

2. the student's assessment of the preparation provided for engaging in this new learning environment.

The purpose of the survey was clearly outlined, participation was optional and consent was gained to anonymously share the research findings.

The survey combined quantitative and qualitative research. Using the Likert scale, students were asked to rate statements provided to them with a view to gauging an overall response to the effectiveness of the model. In addition, an opportunity was provided following each question for them to add any further thoughts or comments. 25 students responded producing a $40 \%$ return.

It should be noted that the researcher/author was also the University Tutor/Practice Educator who supported a group. This brings with it helpful insights having observed the group process and on occasions intervened, whilst also creating inevitable bias in the sense that by the point of evaluating, the researcher/author had a positive view of the potential of

79 J. of Practice Teaching \& Learning: Advance (c) wEb 
this group learning model, having observed the process and witnessed the learning that took place. That said, to develop the model further, it was imperative that critical student feedback was taken on board and therefore it is hoped that bias was minimized and that a balanced report of the findings has been presented.

An electronic questionnaire was chosen as an appropriate method due to being quick to administer and easy to collate information in a short space of time. This was required due to this model having been embedded within the placement experience, with a need to review it's success in a timely fashion and make decisions regarding potential continuation for the next academic year. The information provided in the results section proved useful for this purpose on a practical and functional level. However, semi-structured interviews or focus groups would have allowed for further exploration of student's personal experiences of this group learning environment, and would have allowed more depth to the analysis of how the process furthered the student's learning.

\section{The results}

As outlined above, the questions covered two areas, and these are presented in accordance below.

\section{The students' experiences of the process of peer-led group supervision}

Two key themes emerged from the findings as being positive aspects resulting from this peer-led group experience; the benefits of peer support and the opportunity for knowledge exchange. $84 \%$ of respondents agreed or strongly agreed that it allowed them to share their practice learning experiences with other students, $72 \%$ agreed or strongly agreed that the group prevented a sense of isolation and $62 \%$ agreed or strongly agreed that it enabled them to discuss and reflect on any challenges they were facing on placement. One student commented, 'It was great to meet up with others in the same boat, draw conclusions and support for work I've been doing. Another commented 'it was useful to know that other students were experiencing similar difficulties/anxieties and how they managed to resolve them.

80 J. of Practice Teaching \& Learning: Advance $\odot$ w $\mathcal{E} b$ 
With regard to knowledge exchange, $84 \%$ of respondents agreed or strongly agreed that it increased their awareness of the needs of other service user groups who they didn't have direct contact with on their own placement and 68\% agreed or strongly agreed that the group experience enabled a useful exchange of local knowledge and contacts. One student commented that,

as a student in adult services, I was able to discuss the complexities of my work to others that were in children's services, of which they were unaware' and another stated 'it was useful to know the processes of other agencies that are being worked with. It gave useful insight of where to refer and what interventions were done by other agencies.

In contrast to this very positive review in terms of peer support and knowledge exchange, there was inconclusive evidence regarding other aspects of the specified learning outcomes. Students provided thoughtprovoking, conflicting viewpoints on several key issues. With regard to engagement in the process and the depth of resulting learning, the following comments stood out in stark contrast to each other, representing very different individual experiences and levels of understanding of the process. Several students gave feedback akin to the following student;

it was also helpful to be reminded to consider the theory that was behind the work you were doing as sometimes this was not obvious to me or I had not recognised that was what I was doing.

This suggested a recognized value in the learning process and yet this was contrasted with feedback from other students stating,

there was not the structure to share practice learning' and 'there didn't seem to be a massive emphasis placed on this by my Practice Educator. (referring to theory and legislation)

With regards to skills-rehearsal, there was similar contradictory feedback. For example, whilst one student noted, it was a safe place to practice these skills (chairing and minuting) and consider the skills required to manage this competently', another exclaimed 'if you are unable to chair and minute a small group at this stage then you need to consider what you are doing ...these are 2nd year skills!'

Overall the feedback reflected that the intended learning outcomes had

81 J. of Practice Teaching \& Learning: Advance $\odot$ w Eb 
been achieved for some but not all students.

\section{The student's assessment of the preparation provided for engaging in this new learning environment.}

When asked what they would have liked to be different and what they would change the respondents provided clear and insightful feedback;

- More preparation to partake in the process and fully understand the model

- A clearer definition of the role of the observing Practice Educator/Link Tutor

- More involvement by the tutor in the initial set-up and forming of the group

- A request to bring the groups back 'in-house' so that they are timetabled during academic hours rather than in placement time

- The group should support learning rather than be an additional assessment opportunity for Practice Educators

- A suggestion that this model could replace the more traditional group tutorials led by academic tutors

This student feedback was reassuringly honest and not unexpected from the perspective of all tutors and Practice Educators involved in the pilot. This feedback arose from irritation within groups regarding varying levels of attendance by students, lack of clarity with regard to how participation was being perceived/assessed by the PE/link tutor and considerable time taken trying to convene times and locations that would best suit everyone, within already busy placement schedules.

\section{Observer reflections}

Although not part of the formal evaluation process which focused on student experience and feedback, all PEs involved reported positively on their experiences of these groups. Due to lack of preparation from the outset, each PE interpreted the role differently with some involving themselves more directly in discussions, and others sticking steadfastly to the requirement to only observe. As one of the PEs, I learned through the

82 J. of Practice Teaching E Learning: Advance (C) wEb 
process and responded to my group accordingly. Having begun in a purely observational role, it was clear that my students were floundering with what was required of them - unable to intervene to manage the chattier group members, unclear of the skills they had the opportunity to develop and not really recognizing the wealth of potential learning opportunities that I could see the model offered. Halfway through the placement and on seeing their confusion and dissatisfaction, I stepped in and chaired the next group. This offered a reference point for what the group could look like and quickly changed the dynamic and level of success of the group. From that point forward, I was able to play a low-key role as a participant observer and only step in towards the end of a discussion, if I felt they had missed the opportunity to recognize a piece of theory, legislation or policy that might apply to their practice. Being part of the group rather than an outsider looking on was altogether more comfortable for us all and from my perspective, the group became more meaningful, fun and engaging and so the different elements of learning increased. I became increasingly interested in the incidental learning and how this learning environment could be more transparently introduced and explained so that all students could more easily recognise the potential of the learning process in a group setting with peers. I also recognized the potential for deeper learning about self and others if the opportunity could be made available or built-in to the model, to provide observer feedback about the group dynamics and skills witnessed during the sessions.

\section{Discussion}

In line with existing research the evaluation of this peer support group supervision model was reviewed extremely positively by the students involved, giving strong support to Lindsay's suggestion that group learning opportunities should be provided for all student social workers. The benefits of increased knowledge exchange and cross-placement learning are particularly beneficial in the context of generic social work degree courses. There is not sufficient depth to the qualitative feedback to claim certainty with regard to the detail of the learning process enabled by this learning environment, but student comments suggest that the model successfully allowed 'action learning',

83 J. of Practice Teaching \& Learning: Advance $\odot$ w Eb 
where learners develop insights through tackling real-world issues and coming together to discuss them in a 'set' or structured forum. (Lester and Costley, 2010, p.566)

Revans (1983) states,

it is recognised ignorance, not programmed knowledge that is the key to Action Learning: men [sic] start to learn with and from each other only when they discover that no-one knows the answer but all are obliged to find it. (cited in Jarvis, 2010, p.138)

and these findings suggested that for many students the group experience encouraged them to recognise gaps in their knowledge and skills and proactively seek to further their learning in identified areas. The model provided opportunities for work-based and problem-based learning, whereby the student could be 'regarded as an autonomous self who is making sense of his or her context and role through active participation'.(Tennant, 2004 ,in Lester and Costley, 2010, p.567) Lester and Costley link this to Schon's notion of constructionism,

where knowing and doing coexist in a spiral of activity where knowledge informs practice, which generates further knowledge that in turn leads to change in practice. (Schon 1987 in Lester and Costley, 2010. p.567)

For many students, this spiral of activity was enhanced by participation in peer-led group supervision. It is hoped that this process contributed in part to the process of developing professional identity. However, it is important to return to the results which indicate that many but not all students recognized the benefits of this learning environment and this perhaps links to wider research around groupwork - that it benefits the majority but not always the entirety of a group.

The more critical feedback from students suggests that they maintained a mindset that they should wait for instruction or guidance from a tutor, rather than actively own their part in this less directive learning process. When they didn't receive the instruction which they may have expected from previous educational experiences, their interpretation was that the learning outcomes had not been achieved (for example, they didn't share practice learning experiences or apply theory to practice because no one told them to do so). These experiences link to some of the challenges of peer learning, highlighted by Cohen and Sampson. They note that 'for

84 J. of Practice Teaching \& Learning: Advance $\odot w \mathcal{E} b$ 
many students peer learning is an unfamiliar approach, seemingly at odds with their experience of more individual approaches to learning' and that they may 'expect teachers to control all learning through teaching'. Cohen and Sampson encourage the importance of orienting students to peer learning with transparent, thoughtful and ongoing preparation for this mode of learning (in Boud et al., 2001. pp.52, 62). Notably, in this pilot study, the need for such preparation was under-estimated, and there was limited preparation for students and PE/link tutors, perhaps due to a naive believe that it was obvious how this group format would function. It would therefore be interesting to evaluate this learning experience a further time, with greater time and thought invested in this critical preparatory stage, prior to the groups commencing.

Student feedback identified that a further area which required greater clarity and transparency was the role of the observing PE/link tutor. Students reported feeling confused as to whether they were there to offer a support role or there to undertake an assessment of their performance or contribution within the group. It was unclear if their role was purely observational and thus individual tutors did interpret the role differently. Borders (1991) is helpful in pinpointing key aspects required of a supervisor supporting peer group supervision for counsellors and these role descriptors are entirely appropriate to a PE/Link tutor involved in peer-led group supervision for social work students. Borders notes that as far as the process, the supervisor is initially required to help 'establish a supportive atmosphere that is conducive to open and honest interactions' and then describes two clear functions of the role; as moderator and as process observer. As moderator, the function is to help the group stay on-task and as process observer, it is to observe group dynamics and encourage open discussion around interactions and relationships. To fulfil these roles and functions, 'the effective peer group supervisor must be a skilled teacher, counsellor, consultant or group leader', 'cognizant of the developmental level(s) of peer group members'. They require the skill to assess and respond continually to the needs of the group and the individuals, often operating on many levels in order to help a 'productive learning experience to unfold' (Borders 1991, p.249). Stepping back to allow learning between peers, without tutor intervention, may also be a challenge for some educators who, similar to students, are also accustomed to a view that student learning only takes place in response to direct input from an educator (Sampson and Cohen in Boud et al. 2001).

In the initial design of the model, the potential for experiential learning was missed, and thus the PE/link tutors had not been tasked to provide

85 J. of Practice Teaching \& Learning: Advance $\odot$ wEbb 
feedback to the group from the observer's perspective, which may have prompted further learning and reflection for students, in areas such as practice skills (time management, chairing, minuting) and group dynamics and interactions. In order to maximize the learning potential of this model, $\mathrm{PE} /$ link tutors need to understand the underlying complexities of their role and the innate skills required. Peer support and knowledge exchange will happen in most groups, with little input from a tutor. However, deeper learning around contentious issues, dealing with conflict within the group and incidental learning experiences can only be achieved consistently whereby the tutor role includes a remit to highlight, feedback and challenge group processes and topics of learning, rather than passively observe. This is different from the initial design of the pilot model and a notable learning outcome from this evaluation.

Borders (1991) points to the importance of a stepped approach to supporting peer group supervision; 'the supervisor is more active and directive in novice peer groups' and there is a logic to applying this to peer-led group supervision. As Beets et al (2012) note,

peer review requires a willingness to disclose practice issues and to improve strength of practice knowledge by exposing areas of vulnerability or uncertainty as well as success. (Beets et al 2012. p.7)

For students to feel safe to show this vulnerability, the basic premises of good group work practice need to be met first and it may be too much to expect this environment to be established by a group of student peers. Thus for future groups, it is highly advisable that the observing PE would chair the first couple of group meetings, acting as a role model to ensure that a safe and respectful learning environment is created first, then allowing social work students taking the lead. The intention of a peer-led would be clear from the outset and would follow as soon as the group understood the model and expectations of them, but the PE would have a more active role in creating and then overseeing a safe learning environment.

With regard to future research, a further evaluation with the use of focus groups or semi-structured interview would be of interest to understand more about the learning journeys and processes experienced by students. Given the important focus on developing professional curiosity, reflexivity and professional identity, learning through groups in this way seems very worthwhile and understanding more about what works well and pitfalls to avoid would be very helpful.

86 J. of Practice Teaching \& Learning: Advance $\odot$ w $\& b$ 
This model is also worth considering for students on placement in rural areas with little contact with peers, and/or as part of a blended learning approach. These groups could easily take place via an online platform and could potentially reduce isolation and build skills in communicating within online group experiences. In the wake of COVID-19, student social workers have increasingly been involved in online practice and online supervision and this model could serve as a clearly structured learning environment which encouraged links and learning between students on different placements, enabling connection, discussion and skills-development as part of a distant learning experience. As noted by Fry et al. 'the content-led info-transmission model needn't be the template for online teaching and learning today' (Fry et al. 2014. p.144) and this is a prime example of a group learning environment which could effectively take place online. Provided the platform for delivery is reliable, online delivery offers much freedom and scope such that 'rich student-student interaction, experiential learning, peer feedback and small group learning' can all be achieved.(Fry et al. , 2014. p.142) The key is in the learning design and there is sufficient positive feedback from this peer-led group supervision process to suggest it is worthy of considering how it could be embedded in social work degree courses, both face-to-face and as part of distant-learning courses.

\section{Conclusion}

In conclusion, there are many positive aspects to this model of peer-led group supervision and with further transparency, preparation and clarity of roles, it is hoped that positive learning outcomes can be achieved for even more students as a result of participation in such groups. In Social Work education it is key that students ultimately understand how to become a social worker, rather than presume that teaching sessions will teach them what to do in order to be a social worker and this model allows for greater levels of autonomous thinking, rehearsal of skills and understanding of self within group interactions. In practical terms, these groups will in future be timetabled rather than taking place in placement time and will be considered as a replacement to more traditional group tutorials with academic staff. Transparency and preparation for understanding and undertaking peer-learning will be far greater in future and the supporting PE will be more of a participant observer, such that they can role-model

87 J. of Practice Teaching \& Learning: Advance $\odot$ w Eb 
skills for running the group first and then undertake an ongoing supportive rather than assessment role. With regard to further research, it would be of interest to understand in greater depth the experiences of incidental learning, areas of learning around group dynamics and group interactions and more clearly establish the learning linked to professional skills and leadership and the evolution of professional identity. The worth of peer-learning within this context is confirmed, with the intricacies of the learning that takes place worthy of further exploration.

\section{References}

Barnett, R. (2009) Knowing and becoming in the higher education curriculum. Studies in Higher Education, 34, 4, 429-440

Barr,R. and Tagg, J. (1995) From teaching to learning: A new paradigm for undergraduate education. Higher Education. 60

BASW (2018) The Professional Capabilities Framework (PCF) 2018 Graphic | www. basw.co.uk [accessed 27 April 2021].

Beets, A., Bidois, J., Broom, J., Moore, P. and Swan, L. (2012) Peer review: Supporting reflective practice and connection between social workers. Aotearoa New Zealand Social Work, 24, 2, 3-7

Borders, L,D. 2001 A Systematic approach to peer group supervision. Journal of Counseling and Development, 69 248-252

Boud, D., Cohen, R. And Sampson, J. (2001) Peer Learning in Higher Education. Learning from and with each other. London: Kogan Page

Counselman, E. and Weber, R. (2004). Organizing and maintaining peer supervision groups. International Journal of Group Psychotherapy, 54, 2, 125-143

Crawford, K., Price, M. \& Price, B. (2015) Groupwork Practice for Social Workers. London: Sag

Doel, M. (2010) Social Work Placements: A traveller's guide. Abingdon: Routledge

Fry, H., Ketteridge, S. \& Marshall, S. (Eds) (2014) A Handbook for Teaching and Learning in Higher Education; Enhancing Academic practice. Abingdon: Routledge Jarvis, P. (2010) Adult Education and Lifelong Learning: Theory and practice. Abingdon: Routledge

Kadushin, A. (1992) Supervision in Social Work. New York: Columbia University Press

Lester, S. and Costley, C. 2010 Work-based learning at higher education level: Value, practice and critique. Studies in Higher Education..35, 5, 561-575

88 J. of Practice Teaching \& Learning: Advance $\odot$ w $\& b$ 
Lindsay, T. 2003 An investigation of group learning on practice placements The Higher Education Academy, Social Policy and Social Work (SWAP) Report

Rowell, P. C., \& Benshoff, J. M. (2008). Using personal growth groups in multicultural counseling courses to foster students' ethnic identity development. Counselor Education and Supervision, 48, 1, 2-15

Scales, P. (2017). An Introduction to Learning and Teaching in Higher Education: Supporting fellowship. Maidenhead: McGraw Hill

Showell, W., Kerr, N \& Kerr, J. (2015) Practice Education Social Work Students. Maidenhead: Open University Press

Teater, B. (2014) An Introduction to Applying Social Work Theories and Methods (2nd Ed.)Maidenhead: Open University Press

Topping, K.J., (2005) Trends in peer learning. Educational Psychology. 25, 6, 631-645

Valentino, A. L., LeBlanc, L. A., \& Sellers, T. P. (2016). The benefits of group supervision and a recommended structure for implementation. Behavior Analysis in Practice, 9, 4, 320-328

Wiles, F. (2017). What is professional identity and how do social workers acquire it? in S. Webb, \& A. Stephen (Eds.) Professional Identity and Social Work. Abingdon: Routledge

89 J. of Practice Teaching \& Learning: Advance $\odot$ w $b b$ 